\title{
EM CARTAZ: A FORMAÇÃO DOCENTE E AS REPRESENTAÇÕES DE FAMÍLIAS ORGANIZADAS EM MODELOS NÃO CONVENCIONAIS
}

\author{
EN CARTAZ: LA FORMACIÓN DOCENTE Y LAS REPRESENTACIONES DE \\ FAMILIAS ORGANIZADAS EN MODELOS NO CONVENCIONALES
}

\section{IN POSTER: TEACHING TRAINING AND REPRESENTATIONS OF FAMILIES ORGANIZED IN NON-CONVENTIONAL MODELS}

\author{
Isaias Batista de OLIVEIRA JÚNIOR ${ }^{1}$
}

RESUMO: Este artigo teve como objetivo analisar as representações sociais sobre família entre profissionais do magistério que responderam um inventário do tipo Likert a fim de aferirmos suas representações acerca do conceito de "família", "família ideal" e "família desestruturada". Os dados da pesquisa foram coletados durante a realização de um curso de formação docente intitulado "Formação docente e as representações de famílias organizadas em modelos não convencionais pelas lentes do cinema". Os resultados obtidos revelaram mudanças nas representações dos sujeitos da pesquisa entre o pré e o pós-teste, que se devem, em parte pelo fato de a experiência estética, por meio do cinema, permitir o rompimento com o ideário de família admitindo as diversas maneiras de ser família como verdadeiras.

PALAVRAS-CHAVE: Escola. Famílias organizadas em modelos não convencionais. Cinema. Formação docente.

RESUMEN: Este artículo tuvo como objetivo analizar las representaciones sociales sobre familia entre profesionales del magisterio que respondieron un inventario del tipo Likert a fin de aferir sus representaciones acerca del concepto de "familia", "familia ideal" y "familia desestructurada". Los datos de la encuesta fueron recolectados durante la realización de un curso de formación docente titulado "Formación docente y las representaciones de familias organizadas en modelos no convencionales por las lentes del cine". Los resultados obtenidos revelaron cambios en las representaciones de los sujetos de la investigación entre el pre y el post-test, que se deben, en parte por el hecho de que la experiencia estética, por medio del cine, permite el rompimiento con el ideario de familia admitiendo las diversas maneras De ser familia como verdaderas.

PALAVRAS CLAVE: Escuela. Familias organizadas en modelos no convencionales. Cine. Formación docente.

${ }^{1}$ Universidade Estadual do Paraná (UNESPAR). Professor na Universidade Estadual do Paraná. Doutor em Educação. E-mail: jr_oliveira1979@hotmail.com 
ABSTRACT: This article aimed to analyze the social representations about family among teachers who answered a Likert-type inventory in order to assess their representations about the concept of "family", "ideal family" and "unstructured family". The research data was collected during the course of a teacher training course entitled "Teacher training and representations of families organized in unconventional models by the lenses of the cinema". The results obtained revealed changes in the representations of the subjects of the research between the pre-and post-test, which are due, in part, to the fact that aesthetic experience, through the cinema, allows the rupture with the family ideals, admitting the different ways Of being family as true.

KEYWORDS: School. Families organized in unconventional models. Movie theater. Teacher Training.

\section{Introdução}

Algumas definições disponíveis no que se refere à família na pós-modernidade ainda são deficientes para contemplar os fenômenos atuais das relações familiares, desde a nomenclatura até a descrição de seu funcionamento e função. Provavelmente, a busca de respostas ou (re)definições que deem conta de explicitar a diversidade e complexidade das famílias na atualidade seja um dos maiores desafios nas pesquisas com famílias (WAGNER, 2011).

Diante desse cenário alguns questionamentos nos surgem: quais famílias encontramos com maior frequência em nossas escolas? Seguimos de encontro ou ao encontro delas? Estamos lidando com sabedoria com as transformações da família pósmoderna? Por que a escola ainda localiza na chamada "configuração familiar" um ponto nevrálgico ou uma possível solução para resolver os problemas de (in)disciplina na escola?

Muitas respostas a tais questionamentos favorecem a ineficiência da implementação de estratégias educacionais que objetivam integrar a família no contexto escolar, uma vez que tende a afastar do seu interior as famílias organizadas por modelos não convencionais, que por ela são consideradas desordenadas. Consequentemente, o processo de desenvolvimento dos membros dessas instituições se torna comprometido, devido a sua dissociação.

Defendemos que, o reconhecimento, por parte da escola, das variáveis que compõem as famílias na contemporaneidade possibilitaria a efetivação de estratégias apropriadas de participação conjunta, bem como poderia nos fornecer orientações específicas, respeitando as particularidades familiares, observando suas características 
culturais, os papéis e sua disponibilidade efetiva para concretizar atividades conjuntas com a escola.

Pensando na subversão de conceitos estigmatizantes, vimos como possibilidade de estudo o desenvolvimento de uma metodologia de formação continuada de profissionais da educação, por meio da experiência estética propiciada pela narrativa dos conteúdos fílmicos, que poderá ser incorporada na formação e atuação dos profissionais da educação, como sujeitos espectadores e consumidores do cinema, proporcionando-lhes concretude ao seu trabalho.

Acreditamos que a experiência estética proporcionada pelo cinema em um curso de formação tem a capacidade de problematizar e des/re/construir valores, percepções e padrões adotados ideologicamente pela escola, visto que quando implicada na formação do professor "[...] permiti-lhe experienciar sentimentos que em sua vida ordinária não experimentaria, viabiliza o encontro do sujeito consigo mesmo, na medida em que o põe desnudo, diante de si [...]" (AMORIM, 2007, p. 64) por meio das discussões coletivas que possibilita o desenvolvimento dos indivíduos que estão inseridos no processo.

Banks (2009, p. 18) aponta como uma boa razão para o uso da elicitação de opiniões, por meio da transmissão fílmica ou vídeo elicitação, “[...] o fato de que o estudo de imagens na criação ou coleta de dados pode ser capaz de revelar algum conhecimento sociológico que não é acessível por nenhum outro meio [...]”. Portanto, é recomendável que pesquisas sobre filmes e belas-artes questionem o público-alvo dessas imagens acerca do que ele pensa que elas "significam" e não o "significado" das imagens presumido na leitura do autor do estudo.

Dessa forma, novos questionamos se levantam: o cinema pode contribuir na re/des/contextualização da relação escola-família? Pode o cinema contribuir para a formação docente com vistas a integração com a família?

Partindo dessas indagações, defendemos que é necessário contribuir para a construção de um contexto escolar permeado por posturas profissionais éticas, humanitárias e acolhedoras em educadores de educação infantil e séries iniciais da educação básica, por intermédio da discussão sobre famílias organizadas em modelos não convencionais por meio de projeções fílmicas.

Partindo dessa abordagem, cogitamos ser possível, por meio da experiência estética, eliciar as percepções dos profissionais no sentido de demonstrar que, independentemente da maneira como se organizam, as famílias possuem a capacidade de enfrentamento e de adaptação como uma unidade funcional, ou seja, elas são capazes 
de intervir em situações de estresse, superar crises e enfrentar dificuldades, ajustando-se de forma a intervir no bem-estar de toda sua unidade.

Pautados nesse panorama delineamos o processo interventivo intitulado "Formação docente e as representações de famílias organizadas em modelos não convencionais pelas lentes do cinema" baseado na transmissão de oito obras cinematográficas - "Baby Love; Bella"; "De coração partido"; "Os garotos estão de volta"; "Pelos olhos de Maisie"; "Um dia desses"; "Uma lição de amor" e "A razão do meu afeto" - selecionadas dentre uma coletânea de 38 obras fílmicas, por sua centralidade girar em torno de famílias organizadas em modelos não convencionais e pelas famílias retratadas apresentarem processos chave de resiliência familiar apontados por Walsh (2005) como: sistemas de crença; padrões organizacionais e; processos de comunicação.

Seguido as projeções dos filmes realizamos problematizações das obras com perguntas que levavam as professoras a expressarem seus sentimentos e emoções quanto aos personagens, ao papel da escola no acolhimento da família retratada no filme e à capacidade daquela organização familiar funcionar bem. Posteriormente eram propostas situações problemas, comuns ao cotidiano escolar, envolvendo famílias não convencionais, a serem resolvidas em grupo.

Nesse sentido, esta pesquisa teve por objetivo analisar as condições e possibilidades de formação continuada de professores da Educação Infantil e anos iniciais do Ensino Fundamental, por meio da experiência estética propiciada pelo cinema, com ênfase no trabalho com as percepções, valores e representações docentes, em relação a famílias organizadas em modelos não convencionais.

Analisamos as representações expostas por 15 professoras da Educação Básica no Norte do Paraná sobre o conceito de "família", "família ideal” e "família desestruturada", mediante a aplicação de dois instrumentos de investigação: inventário do tipo Likert e diário de campo, sendo o primeiro instrumento aplicado no momento anterior e posterior à intervenção e o último instrumento registrado durante todo o processo investigativo.

O método baseado na escala Likert tem como pressuposto a estipulação de cinco categorias de resposta (pontos), partindo de conceitos como "aprovo fortemente" até "desaprovo fortemente", por exemplo. Embora o uso de escalas com outros níveis, diferente de cinco, seja possível, não podemos atribuir ao instrumento o conceito de 
escala Likert, mas sim do tipo Likert, mesmo que continuem a representar uma escala de classificação (DALMORO; VIEIRA, 2013).

Dessa forma, em nosso estudo, empregamos um questionário do tipo Likert, no pré e no pós-teste, em que o participante deveria assinalar uma alternativa, partindo do nível "concordo", "não discordo e nem concordo" - a utilização do ponto neutro é defendida por Dalmoro e Vieira (2013) por ser uma opção que deixa o respondente mais à vontade no momento de expressar sua opinião - e "discordo", em relação a 23 (vinte e três) afirmações referentes à forma de organização familiar, envolvendo suas percepções e valores a respeito de diferentes configurações familiares, sendo que elas foram aplicadas em ordem aleatória e agrupadas após a coleta de dados.

Para a análise dos resultadosusamos o software SPSS, versão 14.0, com o intuito de apresentar as frequências dos níveis de concordância ou discordância de itens referentes à "família tradicional", "família desestruturada" e "família ideal", além disto, verificar, por meio do teste não paramétrico de Wilcoxon, se há diferença significativa entre as duas situações estudadas: pré-intervenção e pós-intervenção, considerando o nível de significância de 5\%. O uso de teste não paramétrico foi necessário pelo fato dos itens estudados apresentarem escala Likert com 03 pontos (escala ordinal) e pela amostra estudada ser pequena, não satisfazendo as exigências para a aplicação do teste t-Student (SIEGEL, 1956).

Nas discussões que seguem, apresentamos os resultados estatísticos das questões, agrupadas em três categorias: "família", "família desestruturada" e "família ideal". Por fim, apresentamos nossas percepções acerca do panorama ofertado pela análise estatística.

\section{Família}

As frases afirmativas que se referiam ao conceito de "família" foram apresentadas junto às questões que versavam sobre as demais categorias de análise, que serão discutidas na sequência, tais como: família desestruturada e família ideal.

Depois de respondido os níveis de concordância, discordância ou neutralidade, os resultados foram analisados por meio do teste não paramétrico de Wilcoxon, em que podemos observar se houve ou não diferenças significativas nos dois momentos da pesquisa, no que se refere ao pré- e ao pós-teste. 
Tabela 1: Família

\begin{tabular}{|c|c|c|c|c|c|c|c|c|c|c|c|c|}
\hline \multicolumn{13}{|c|}{ FAMÍLIA } \\
\hline & \multicolumn{6}{|c|}{ Pré-teste } & \multicolumn{6}{|c|}{ Pós-teste } \\
\hline & \multicolumn{2}{|c|}{ Discordo } & \multicolumn{2}{|c|}{$\begin{array}{l}\text { Nem } \\
\text { concordo } \\
\text { nem } \\
\text { discordo }\end{array}$} & \multicolumn{2}{|c|}{ Concordo } & \multicolumn{2}{|c|}{ Discordo } & \multicolumn{2}{|c|}{$\begin{array}{c}\text { Nem } \\
\text { concordo } \\
\text { nem } \\
\text { discordo }\end{array}$} & \multicolumn{2}{|c|}{ Concordo } \\
\hline & $f$ & $\%$ & $f$ & $\%$ & $f$ & $\%$ & $f$ & $\%$ & $f$ & $\%$ & $f$ & $\%$ \\
\hline \multirow{2}{*}{$\begin{array}{l}\text { Família é todo e qualquer } \\
\text { agrupamento de pessoas onde } \\
\text { permeie o afeto, ou seja, todo e } \\
\text { qualquer grupo no qual os seus } \\
\text { membros enxergam uns aos } \\
\text { outros como seu familiar }\end{array}$} & 0 & 0,0 & 2 & 13,3 & 13 & 86,7 & 0 & 0,0 & 1 & 6,7 & 14 & 93,3 \\
\hline & \multicolumn{12}{|c|}{ P-valor teste de Wilcoxon: 0,564} \\
\hline $\begin{array}{l}\text { Toda e qualquer forma de } \\
\text { organização familiar tem a } \\
\text { capacidade de responder } \\
\text { efetivamente às demandas da }\end{array}$ & 3 & 20,0 & 1 & 6,7 & 11 & 73,3 & 1 & 6,7 & 2 & 13,3 & 12 & 80,0 \\
\hline $\begin{array}{l}\text { vida quotidiana, assumindo o } \\
\text { cuidado e o compromisso com } \\
\text { sua própria vida e a daqueles } \\
\text { que delas dependem }\end{array}$ & \multicolumn{12}{|c|}{ P-valor teste de Wilcoxon: 0,180} \\
\hline
\end{tabular}

Fonte: Elaborado pelo autor (2015).

Podemos observar, na Tabela 01, que as frases correspondentes às categorias "família": "Família é todo e qualquer agrupamento de pessoas onde permeie o afeto, ou seja, todo e qualquer grupo no qual os seus membros enxergam uns aos outros como seu familiar", bem como "Toda e qualquer forma de organização familiar tem a capacidade de responder efetivamente às demandas da vida quotidiana, assumindo o cuidado e o compromisso com sua própria vida e a daqueles que delas dependem", não apresentaram diferença estatística entre as situações de pré- e pós-intervenção por meio do teste. Elas apresentaram ( $p$-valor $>0,05)$, indicando que os valores de concordância com ambas às informações foram muito semelhantes em ambos os momentos, de $86,7 \%$ para $93,3 \%$ na primeira assertiva e $73,3 \%$ para $80 \%$ na segunda.

\section{Família desestruturada}

A tabela 2 aponta os índices obtidos pré- e pós intervenção, no que se refere à "família desestruturada". A elaboração das frases foi previamente pensada pelos autores, associando fatores referentes tanto à organização quanto ao funcionamento 
familiar, com o intuito de averiguar possíveis propensões dos respondentes, a um ou outro aspecto, ou mesmo ambos:

Tabela 2: Família desestruturada

\section{FAMÍLIA DESESTRUTURADA}

\begin{tabular}{|c|c|c|c|c|c|c|c|c|c|c|c|c|}
\hline & \multicolumn{6}{|c|}{ Pré-teste } & \multicolumn{6}{|c|}{ Pós-teste } \\
\hline & \multicolumn{2}{|c|}{ Discordo } & \multicolumn{2}{|c|}{$\begin{array}{l}\text { Nem } \\
\text { concordo } \\
\text { nem } \\
\text { discordo }\end{array}$} & \multicolumn{2}{|c|}{ Concordo } & \multicolumn{2}{|c|}{ Discordo } & \multicolumn{2}{|c|}{$\begin{array}{l}\text { Nem } \\
\text { concordo } \\
\text { nem } \\
\text { discordo }\end{array}$} & \multicolumn{2}{|c|}{ Concordo } \\
\hline & $F$ & $\%$ & $f$ & $\%$ & $f$ & $\%$ & $f$ & $\%$ & $f$ & $\%$ & $f$ & $\%$ \\
\hline \multirow{2}{*}{$\begin{array}{l}\text { Famílias desestruturadas são } \\
\text { aquelas em que falta a } \\
\text { presença paterna ou materna. }\end{array}$} & 8 & 53,3 & 4 & 26,7 & 3 & 20,0 & 12 & 80,0 & 3 & 20,0 & 0 & 0,0 \\
\hline & \multicolumn{12}{|c|}{ P-valor teste de Wilcoxon: 0,053} \\
\hline \multirow{2}{*}{$\begin{array}{l}\text { Famílias desestruturadas são } \\
\text { aquelas em que não há regras } \\
\text { claras e definidas e isso não } \\
\text { tem nenhuma relação com o } \\
\text { tipo de família. }\end{array}$} & 2 & 13,3 & 4 & 26,7 & 9 & 60,0 & 3 & 20,0 & 1 & 6,7 & 11 & 73,3 \\
\hline & \multicolumn{12}{|c|}{ P-valor teste de Wilcoxon: 0,705} \\
\hline \multirow{2}{*}{$\begin{array}{l}\text { Alunos oriundos de famílias } \\
\text { desestruturadas apresentam } \\
\text { desvios de comportamentos e } \\
\text { problemas de aprendizagem } \\
\text { escolar. }\end{array}$} & 1 & 6,7 & 5 & 33,3 & 9 & 60,0 & 2 & 13,3 & 10 & 66,7 & 3 & 20,0 \\
\hline & \multicolumn{12}{|c|}{ P-valor teste de Wilcoxon: 0,020} \\
\hline \multirow{2}{*}{$\begin{array}{l}\text { Crianças educadas por outros } \\
\text { tipos de família, que não seja } \\
\text { a tradicional, serão adultos } \\
\text { desajustados e propensos à } \\
\text { delinquência juvenil, a a } \\
\text { violência, as drogadições e a } \\
\text { desorientação. }\end{array}$} & 11 & 73,3 & 4 & 26,7 & 0 & 0,0 & 14 & 93,3 & 0 & 0,0 & 1 & 6,7 \\
\hline & \multicolumn{12}{|c|}{ P-valor teste de Wilcoxon: 0,480} \\
\hline \multirow{2}{*}{$\begin{array}{l}\text { Pais ou mães solteiros têm } \\
\text { mais dificuldades em educar } \\
\text { seus filhos devido à ausência } \\
\text { de uma figura masculina ou } \\
\text { feminina. }\end{array}$} & 11 & 73,3 & 2 & 13,3 & 2 & 13,3 & 14 & 93,3 & 1 & 6,7 & 0 & 0,0 \\
\hline & \multicolumn{12}{|c|}{ P-valor teste de Wilcoxon: 0,059} \\
\hline \multirow{2}{*}{$\begin{array}{l}\text { Famílias homossexuais não } \\
\text { conseguem educar seus filhos } \\
\text { pela ausência da figura } \\
\text { masculina ou feminina. }\end{array}$} & 12 & 80,0 & 3 & 20,0 & 0 & 0,0 & 13 & 86,7 & 2 & 13,3 & 0 & 0,0 \\
\hline & \multicolumn{12}{|c|}{ P-valor teste de Wilcoxon: 0,317} \\
\hline \multirow{2}{*}{$\begin{array}{l}\text { As famílias } \quad \text { da } \\
\text { contemporaneidade não são } \\
\text { mais semelhantes à de nossos } \\
\text { ancestrais. }\end{array}$} & 0 & 0,0 & 2 & 13,3 & 13 & 86,7 & 0 & 0,0 & 3 & 20,0 & 12 & 80,0 \\
\hline & \multicolumn{12}{|c|}{ P-valor teste de Wilcoxon: 0,564} \\
\hline
\end{tabular}

Fonte: Elaborado pelo autor (2015). 
Utilizando o nível de significância de 5\%, é possível observarmos que na categoria "família desestruturada" houve alterações estatisticamente relevantes, em duas afirmativas: "famílias desestruturadas são aquelas em que falta a presença paterna ou materna" e "alunos oriundos de família desestruturadas apresentam desvios de comportamentos e problemas de aprendizagem escolar", nas situações de pré- e pósteste, obtivemos $(p$-valor $<0,05)$.

$53,3 \%$ das respondentes discordavam da primeira afirmativa no momento da pré-intervenção. Após a intervenção, $80 \%$ passou a discordar que famílias sem a presença paterna ou materna sejam famílias com mau funcionamento, apresentando um P-valor teste de Wilcoxon: 0,053.

Quanto à segunda proposição, que teve alterações estatísticas significativas, elencada na terceira ordem da tabela 2, 60\% assinalou concordância e 33,3\% não concordava e nem discordava dessa afirmação no pré-teste, sendo que o número de concordância caiu para $20 \%$ e o de neutralidade subiu para $66,7 \%$ no pós-teste, com $P$ valor teste de Wilcoxon: 0,020.

Em suma, inicialmente, mais da metade das professoras concordava com a afirmação de que alunos advindos de famílias desestruturadas apresentam desvios de comportamentos e problemas de aprendizagem escolar e aproximadamente um terço das entrevistadas não tinha uma opinião manifesta sobre o assunto. Após o programa de intervenção, um quinto das respondentes continuou a concordar com essa afirmação e o índice de neutralidade praticamente dobrou.

A assertiva destacada na segunda posição da tabela 2: "Famílias desestruturadas são aquelas em que não há regras claras e definidas e isso não tem nenhuma relação com o tipo de família", teve um índice de constância nos dois momentos de aplicação do questionário, sendo que de $60 \%$ no pré-teste, houve um incremento de $13 \%$ no nível de concordância no pós-teste. Essa diferença não pode ser detectada estatisticamente e, portanto, não pode ser considerada como uma mudança representativa.

Perquiridas se "crianças educadas por outros tipos de família, que não seja a tradicional, serão adultos desajustados e propensos à delinquência juvenil, a violência, as drogadições e a desorientação" e "Pais ou mães solteiros têm mais dificuldades em educar seus filhos devido à ausência de uma figura masculina ou feminina", as participantes mantiveram o posicionamento de discordância desses aspectos, em ambas as proposições, de $73,3 \%$ para $93,3 \%$, respectivamente, no momento anterior e posterior a intervenção, não refletindo estatisticamente nos momentos pré- e pós-intervenção. 
O olhar positivo sobre a família homossexual foi perceptível nos resultados do pré-teste, mantido ao longo do processo de formação, bem como no pós-teste. Quando questionadas se "Famílias homossexuais não conseguem educar seus filhos pela ausência da figura masculina ou feminina", $80 \%$ das educadoras discordaram da afirmativa no primeiro momento e $86,7 \%$ após a intervenção negou esse pressuposto.

Um total de $86,7 \%$ concordou que "As famílias da contemporaneidade não são mais semelhantes à de nossos ancestrais" no pré-teste, sendo que $80 \%$ do total de respondentes ma

nteve esse posicionamento após a intervenção empregando o cinema.

\section{Família ideal}

O conceito de "família ideal" foi abordado de maneira a verificar se as percepções das respondentes possuem relações com a configuração de família ou com o funcionamento familiar. Assim, as questões variam entre a concordância e a discordância de determinadas características dessas organizações.

Tabela 3: Família ideal

FAMÍLIA IDEAL

\begin{tabular}{|c|c|c|c|c|c|c|c|c|c|c|c|c|}
\hline & \multicolumn{6}{|c|}{ Pré-teste } & \multicolumn{6}{|c|}{ Pós-teste } \\
\hline & \multicolumn{2}{|c|}{ Discordo } & \multicolumn{2}{|c|}{$\begin{array}{c}\text { Nem } \\
\text { concordo } \\
\text { nem } \\
\text { discordo }\end{array}$} & \multicolumn{2}{|c|}{ Concordo } & \multicolumn{2}{|c|}{ Discordo } & \multicolumn{2}{|c|}{$\begin{array}{c}\text { Nem } \\
\text { concordo } \\
\text { nem } \\
\text { discordo }\end{array}$} & \multicolumn{2}{|c|}{ Concordo } \\
\hline & $f$ & $\%$ & $f$ & $\%$ & $f$ & $\%$ & $f$ & $\%$ & $f$ & $\%$ & $f$ & $\%$ \\
\hline \multirow{2}{*}{$\begin{array}{l}\text { A família ideal é aquela cujo } \\
\text { núcleo é formado por pais e } \\
\text { filhos unidos a partir do } \\
\text { casamento regulado e } \\
\text { regulamentado pelo Estado, } \\
\text { considerada como família } \\
\text { tradicional. }\end{array}$} & 2 & 13,3 & 10 & 66,7 & 3 & 20,0 & 14 & 93,3 & 1 & 6,7 & 0 & 0,0 \\
\hline & \multicolumn{12}{|c|}{ P-valor teste de Wilcoxon: 0,001} \\
\hline \multirow{2}{*}{$\begin{array}{l}\text { Mesmo que existam outros } \\
\text { modelos de famílias, } \\
\text { predomina no cenário } \\
\text { escolar brasileiro a família } \\
\text { tradicional. }\end{array}$} & 1 & 6,7 & 4 & 26,7 & 10 & 66,7 & 3 & 20,0 & 6 & 40,0 & 6 & 40,0 \\
\hline & \multicolumn{12}{|c|}{ P-valor teste de Wilcoxon: 0,034} \\
\hline \multirow{2}{*}{$\begin{array}{l}\text { Apenas as famílias } \\
\text { tradicionais } \\
\text { superar as adversidades e } \\
\text { buscar soluções saudáveis } \\
\text { para o desenvolvimento de } \\
\text { seus membros. }\end{array}$} & 12 & 80,0 & 3 & 20,0 & 0 & 0,0 & 13 & 86,7 & 2 & 13,3 & 0 & 0,0 \\
\hline & \multicolumn{12}{|c|}{ P-valor teste de Wilcoxon: 0,317} \\
\hline
\end{tabular}




\begin{tabular}{|c|c|c|c|c|c|c|c|c|c|c|c|c|}
\hline \multirow{2}{*}{$\begin{array}{l}\text { O casamento é o único } \\
\text { instituto formador e } \\
\text { legitimador da família } \\
\text { brasileira. }\end{array}$} & 10 & 66,7 & 5 & 33,3 & 0 & 0,0 & 11 & 73,3 & 3 & 20,0 & 1 & 6,7 \\
\hline & \multicolumn{12}{|c|}{ P-valor teste de Wilcoxon: 0,999 } \\
\hline \multirow{2}{*}{$\begin{array}{l}\text { Do ponto de vista religioso, } \\
\text { a família constituída pelo } \\
\text { homem e pela mulher é o } \\
\text { modelo ideal de união. }\end{array}$} & 0 & 0,0 & 1 & 6,7 & 14 & 93,3 & 3 & 20,0 & 1 & 6,7 & 11 & 73,3 \\
\hline & \multicolumn{12}{|c|}{ P-valor teste de Wilcoxon: 0,063} \\
\hline \multirow{2}{*}{$\begin{array}{l}\text { A função primordial do } \\
\text { casamento está associada à } \\
\text { procriação. }\end{array}$} & 7 & 46,7 & 4 & 26,7 & 4 & 26,7 & 12 & 80,0 & 3 & 20,0 & 0 & 0,0 \\
\hline & \multicolumn{12}{|c|}{ P-valor teste de Wilcoxon: 0,038} \\
\hline
\end{tabular}

Fonte: Elaborado pelo autor (2015).

Observando a tabela 3, é possível notarmos que o teste de Wilcoxon apontou diferenças significativas, $p$-valor $<0,05$ nas situações de pré- e pós-intervenção para três afirmativas.

Na preposição: "a família ideal é aquela cujo núcleo é formado por pais e filhos unidos a partir do casamento regulado e regulamentado pelo Estado, considerada como família tradicional" predominava no pré-teste a neutralidade, sendo que $66,7 \%$ das educadoras não concordavam e nem discordavam dessa afirmação, ao passo que $20 \%$ tomava esse pressuposto como verdadeiro. Esse dado sofreu alterações com $P$-valor teste de Wilcoxon: 0,001 após o Programa de Formação Continuada, pois, ao reaplicá-lo no pós-teste, foi possível perceber que 93,3\% das participantes passaram a discordar dessa prerrogativa e ninguém mais concordou com tal aspecto.

No que se refere à assertiva: "mesmo que existam outros modelos de famílias, predomina no cenário escolar brasileiro a família tradicional”, no pré-teste, $66,7 \%$ concordava e $26,7 \%$ não concordava e nem discordava dessa afirmativa. No pós-teste, por sua vez, os resultados tanto de concordância quanto de neutralidade figuraram em 40\%, apresentando um P-valor teste de Wilcoxon: 0,034.

Por fim, a terceira questão desse agrupamento de assertivas, que apresentou significância estatística, com P-valor teste de Wilcoxon de 0,038, foi aquela que abordou o seguinteconteúdo: “a função primordial do casamento está associada à procriação", sendo que o nível de discordância praticamente dobrou do pré- para o pósteste, de $46,7 \%$ para $80 \%$ e o número de concordância de $26,7 \%$ acabou por zerar após a intervenção.

Do número de participantes da coleta no pré-teste, $80 \%$ discordou que "apenas as famílias tradicionais conseguem superar as adversidades e buscar soluções saudáveis 
para o desenvolvimento de seus membros", havendo um incremento de $6,7 \%$ nesse número no pós-teste - valor não significativo estatisticamente.

Quanto à afirmação de que "O casamento é o único instituto formador e legitimador da família brasileira”, 66,7\% das participantes da pesquisa a refutaram no pré-teste e no pós-teste $73,3 \%$.

As educadoras defenderam que, "do ponto de vista religioso, a família constituída pelo homem e pela mulher é o modelo ideal de união" com 93,3\% no préteste e $73,3 \%$ no pós-teste. Nessa questão, pairou a dúvida se elas concordavam com esse posicionamento, ou se elas afirmaram que a igreja postula a família constituída pelo homem e a mulher como algo sagrado, condenando as organizações que não se adequam a esse modelo.

\section{Análise Global do resultado do inventário baseado na Escala Likert}

Ao analisar os resultados obtidos no questionário baseado na Escala Likert, no que se refere ao conceito de "família", empregando o Teste de Wilcoxon, com p-valor < 0,05, não percebemos mudanças significativas de conceitos relacionados ao pré- e ao pós-teste. Podemos inferir duas possibilidades para esse dado: a primeira é que o número reduzido de assertivas - 02 ao todo - limitou a categorização do conceito, uma vez que a escolha do número de itens na escala, bem como o número de questões da categoria, pode ter impactado também nos testes estatísticos.

A segunda suspeita se refere ao conceito positivado das professoras acerca das representações de família, como sendo todo e qualquer agrupamento de pessoas em que permeie o afeto, ou seja, todo e qualquer grupo em que os seus membros enxergam uns aos outros como seu familiar. Afinal, como afirma uma professora, “[...] independentemente do tipo de família e como ela se constitui, é o amor e a amizade do lar e que faz com que nos tornemos pessoas realizadas.", de tal maneira que tenhamos a capacidade de responder efetivamente às demandas da vida quotidiana, assumindo o cuidado com nossa própria vida e com a daqueles que de nós dependem. O cinema, enquanto experiência estética veio apenas fortalecer as percepções que as professoras mantiveram ao longo da pesquisa.

Quando nos referimos aos conceitos de "família desestruturada", na assertiva que "Famílias desestruturadas são aquelas em que falta a presença paterna ou materna" 
tivemos alterações significativas nos níveis de discordância do pré- para o pós-teste. Atribuímos esse resultado à experiência estética vivenciada por meio da projeção dos filmes, pois é “[...] a relação que o homem estabelece com o ambiente, com a realidade, com os fatos diários, sustentada pela sensibilidade, que possibilita a leitura polissêmica do mundo, bem diversa da habitual e cotidianamente realizada pelo indivíduo." (AMORIM, 2007, p. 77).

As obras fílmicas, como: "A razão do meu afeto", "Baby love, Bella", "Os garotos estão de volta", "Um Dia Desses e Uma lição de amor", facilitaram a mudança na percepção/entendimento das professoras, pois retratavam famílias caracterizadas pela ausência do pai ou da mãe, mas que apresentavam características que as capacitaram, em determinados momentos das narrativas, a responderem de forma efetiva e proativa às adversidades que se levantavam, assumindo o compromisso com o bom funcionamento familiar.

Quanto à afirmativa: "alunos oriundos de famílias desestruturadas apresentam desvios de comportamentos e problemas de aprendizagem escolar", novamente, tivemos alterações estatísticas relevantes. Inicialmente, no momento da pré-intervenção, as professoras reproduziram o discurso da "família desestruturada", como sendo, em partes, responsável pelo fracasso escolar, no que se refere à aprendizagem escolar formal e à aquisição de regras básicas da convivência humana devido a sua configuração.

Esse posicionamento foi perceptível nas falas de algumas professoras obtidas no diário de campo: "Vemos também, falhas na educação, [...] que devido à falta dos pais, as crianças, às vezes, apresentam várias dificuldades, tanto comportamental, que é a mais comum, como tantas outras.".

A criança, “[...] ao chegar ao ambiente escolar, muitas vezes é tratada com discriminação, não só pelos colegas, mas, infelizmente pelo próprio corpo docente da instituição" - afirmou uma professora, ao fazer referência aos alunos que advêm de famílias com mau funcionamento.

A adoção de parâmetros distanciados dos modelos tradicionais de família, que a escola e os professores muitas vezes defendem, leva-os ao estranhamento em relação a esses “novos pais e mães”. Essa visão pode se manifestar de forma velada ou explícita, intra e extramuros escolares, ou nos sistemas de informação mundial e acabam por se fortalecer diante das incertezas, tanto das famílias como das escolas, que se acusam 
mutuamente, desconsiderando o movimento e a dinâmica dos distintos fatores que estão na base desses sistemas ecológicos (WALSH, 2005).

Embora possamos reconhecer que educadores compreendam que a família seja fundamental para o desenvolvimento integral das crianças, não é concebível responsabilizá-las pela qualidade do desempenho escolar dos alunos, pautado em sua organização, pois o bom ou o mau desempenho escolar não depende exclusivamente da sua configuração. "Outros inúmeros fatores (sociais, políticos, econômicos e culturais) [e de funcionamento interno da família] influem no desempenho, bem como no sucesso ou no fracasso escolar dos alunos, inclusive o tipo de participação requerido de qualquer espécie de família [...]” (OLIVEIRA JÚNIOR; MORAES; COIMBRA, 2015, p. 272), bem como de elementos próprios da organização escolar e da prática do professor.

Após o "Programa de formação de professores e experiência estética: representações de resiliência em famílias não convencionais pelas lentes do cinema", parte considerável das professoras deixaram de afirmar, taxativamente, que as famílias em desordem potencializam as dificuldades de aprendizagem ou possíveis transtornos por parte dos alunos. No entanto, a neutralidade imperou nesse momento, como se a família não pudesse ser culpabilizada, tampouco isenta da responsabilidade do sucesso ou do fracasso escolar.

Essa imparcialidade se deve, em parte, à visão de algumas educadoras de que a família, independentemente de como ela se organiza, não deve ser considerada como o único contexto que a criança tenha a possibilidade de experienciar e expandir seu repertório como indivíduo, em termos de aprendizagem e desenvolvimento. Apesar disto, reflete uma queixa de parte do professorado, com relação ao afastamento da família do âmbito escolar, delegando exclusivamente a escola todo o processo de formação do ser social, como aponta uma professora:

“O correto é que a criança venha com uma base de educação de casa e muitas vezes nos deparamos com a triste realidade, que devido à correria do dia a dia, os pais estão deixando de lado a educação dos filhos e isso é lamentável, sendo assim, a criança deixa de obter informações que são necessárias para sua vida, tanto familiar quanto social.".

Assim, é essencial que a escola não se negue como partícipe do desenvolvimento integral do cidadão, pois, com a ampliação da jornada escolar e consequente permanência do aluno na instituição, cada vez mais, tem se atribuído a escola a tarefa de educar as crianças. Dito de outra forma, à escola, para além das suas funções básicas, 
tem sido imputada a missão de transmitir valores e princípios éticos e morais para convivência harmoniosa de seus alunos em sociedade, uma tarefa que, outrora, era exclusiva das famílias.

Corroborando essa prerrogativa, uma professora defendeu: “[...] as crianças vão cedo para a escola, chegam cedinho vão só à tarde, quase noite para casa. Por este motivo é rotina ver a equipe da escola dar educação para as crianças. Por que digo isso? Pois se as crianças vão cedo, todavia, elas terão regras que serão dadas pelos orientadores, por exemplo: quando se sentar, quando se alimentar, quando e como falar, coisas que como disse eram feitas pela família [...]”.

As demais questões não apresentaram alterações significativas entre os dados obtidos no pré- e no pós-teste e, nesse caso, acreditamos que as prerrogativas iniciais das respondentes foram fortalecidas pela experiência estética, por meio do cinema, pois os resultados se mantiveram muito próximos nos dois momentos da pesquisa. Temos como hipótese que isto se deve ao olhar positivo que as educadoras já possuíam acerca das famílias, atribuindo ao mau funcionamento delas a ausência de normas claras e condutas de convivência e não os aspectos que estejam atrelados a sua configuração, como podemos observar no discurso de uma professora: “[...] é preciso desalinhar-se dessa velha concepção [de família desestruturada] e dar ênfase maior no que ela realmente representa. Sua base não são as pessoas que a constitui, mas o amor incondicional que predomina nesse lar.".

Em uma breve síntese do que foi discutido sobre o termo "família desestruturada", as professoras associaram seu conceito ao funcionamento familiar e não a sua configuração, pois, nas palavras das educadoras, “[...] o fator que define uma família não deve estar baseado em sua estrutura, mas sim no carinho e nas demonstrações de amor", portanto "defino família como um lugar onde recebemos afeto, independentemente de seu formato.".

No agrupamento de questões que debatiam o conceito de "família ideal", foram pontuados aspectos importantes para a nossa compreensão do ideário que as participantes possuíam no momento pré-intervenção e que se modificaram no momento pós-interventivo.

Na afirmativa: "a família ideal é aquela cujo núcleo é formado por pais e filhos unidos a partir do casamento regulado e regulamentado pelo Estado, considerada como família tradicional" predominou, no pré-teste, a neutralidade, ou seja, as respondentes nem concordaram e tampouco discordaram dessa prerrogativa. 
Diante desse posicionamento, é válido considerarmos que “[...] o princípio da pluralidade das formas de família, teve seu marco histórico na Constituição da República de 1988, que trouxe inovações ao romper com o modelo familiar fundado unicamente no casamento, ao dispor sobre outras formas de família [...]” (PEREIRA, 2004, p. 117), passando a regular outros modelos familiares, como, por exemplo, a união estável e família monoparental.

A partir de então, muito se avançou no conceito de família, que deixou de ser uma entidade prevista legalmente apenas quando há o casamento regulamentado pelo Estado. Sendo assim, devemos reconhecer que,

[...] sem dúvida alguma, é o princípio da dignidade da pessoa humana (art. $1^{\circ}$, III) o principal marco de mudança do paradigma da família. A partir dele, tal ente passa a ser considerado um meio de promoção pessoal dos seus componentes. Por isso, o único requisito para a sua constituição não é mais jurídico e sim fático: o afeto. Nessa esteira, observa-se que a entidade familiar ultrapassa os limites da previsão jurídica [...] para abarcar todo e qualquer agrupamento de pessoas onde permeie o elemento afeto (ALVES, 2007, p. 330).

No entanto, o engessamento provocado pela lógica que rege a sociedade, onde reinava a moderna família burguesa, acabou perpassando gerações e constituindo o ideário de um modelo de família supostamente ideal e perfeito, como afirma Kehl (2003, p. 189), e que refletiu na coleta dos dados iniciais da pesquisa.

"É necessário que a sociedade abra os olhos para nossa realidade e inclua todas as formas de famílias na lei.", defendeu uma professora.

A mudança dessa perspectiva se deu após o Programa de Formação Continuada, uma vez que grande parte das educadoras passou a discordar dessa afirmativa. Podemos afiançar, sustentados em Coelho (2012), que a sensibilização estética, por meio do cinema, foi uma ferramenta importante no estabelecimento desses novos códigos e repertórios simbólicos, pois as narrativas fílmicas, contribuíram para essa re/des/construção do imaginário coletivo, ao traduzir percepções legitimadas da família, como um agrupamento "[...] regido pela lei menos confiável entre os humanos: a lei dos afetos [...]" (KEHL, 2003, p. 02).

As narrativas fílmicas serviram como base para a re/significação do conceito de família, como algo que integra o universo das interpretações atribuídas pelos indivíduos e que caracterizam as interações sociais. A partir do momento que as educadoras captaram esses sentidos, passaram a compreender parte da rede simbólica constituinte das atuais famílias de nossa sociedade (ROUDINESCO, 2003). 
Quanto à questão: "mesmo que existam outros modelos de famílias, predomina no cenário escolar brasileiro a família tradicional", os níveis de concordância e neutralidade se equipararam no pós-teste. De certa forma, mesmo as professoras reconhecendo a existência de distintas configurações familiares, continuavam, nos momentos de pré- e pós intervenção, a afirmar que, quantitativamente, a família tradicional ainda predomina sobre as demais configurações familiares, ou, então, em ambas as situações, optaram por não definir um ponto de vista rígido, assumindo a neutralidade ou a dúvida quanto à exatidão da informação.

Devemos ressaltar que o Censo de 2010 nos aponta para 19 configurações familiares ou níveis de parentesco, contra outros 11 detectados no Censo de 2000. Nessa última amostragem, a família tradicional se fez presente em 49,9\% dos lares visitados, ao passo que em 50,1\% das casas a família adquiriu novos contornos (IBGE, 2010).

As possíveis combinações e arranjos familiares são características dos novos lares brasileiros, que variam enormemente de acordo com a fluidez com que seus membros se movimentam. Há dados que apontam que a proporção de brasileiros divorciados aumentou de $1,7 \%$ em 2000, para 3,1\% em 2010, ao passo que o índice de casados caiu de $37 \%$ para 34,8\% em uma década (IBGE, 2010). Ao mesmo tempo, em 2010, o índice de casamentos no civil e religioso teve um índice de 42,9\% contra 49,4\% em 2000, sendo que, dessas pessoas que estava em união conjugal consensual, 6,1\% já havia passado por outro casamento, portanto, eram divorciados (IBGE, 2010).

Atualmente 54,9\% das famílias do Brasil são formadas por casais e filhos. Desse montante, $16,3 \%$ possui filhos de apenas um dos parceiros, ou frutos de relacionamentos anteriores de ambos os parceiros, o que consiste em um forte indício de uniões reconstituídas (IBGE, 2010).

Possivelmente, no Censo de 2020, teremos alterações significativas nesses índices, o que nos fornecerá um novo panorama acerca das famílias, que visivelmente mudarão suas formas. Tais mudanças são significativas não apenas na sociedade, mas na indústria do imaginário pós-moderno, no cinema, na mídia, na televisão e em nossas próprias relações.

Acreditamos que nesse ponto da pesquisa, as professoras assumiram a neutralidade, ou a concordância com tal afirmação, talvez, pelo fato de não terem conhecimento aprofundado desses dados, sendo que essas informações não foram discutidas no Curso de Formação. Outro aspecto que talvez tenha influenciado esse 
ponto de vista se deve ao período de turbulência pelo qual passávamos, com a enquete do Portal da Câmara, incluída em 11 de fevereiro de 2014.

Para conhecimento do leitor, a referida pesquisa tinha por objetivo avaliar se os cidadãos eram favoráveis ou contrários ao conceito incluído no Projeto de Lei 6583/13, do deputado Anderson Ferreira (PR-PE), que cria o Estatuto da Família, por meio do seguinte questionamento: "Você concorda com a definição de família como núcleo formado a partir da união entre homem e mulher, prevista no projeto que cria o Estatuto da Família?”.

As contendas acerca dessa premissa se alastraram como rastilho de pólvora nas redes sociais, formando correntes contrárias - em parte por movimentos sociais, como o Movimento LGBT, Movimento Feminista, dentre outros - e favoráveis - em parte proposta por fundamentalistas religiosos -, vindo a culminar na aprovação com $52.86 \%$ dos votos favoráveis a essa definição, contra $46.76 \%$, contrários e $0,38 \%$ não possui uma opinião formada.

Percebemos o reflexo dessa pesquisa no discurso de uma professora: "Em 2015, o Estatuto da Família defendeu que família é formada a partir da união de um homem e uma mulher $[\ldots]$.

Ainda no agrupamento das questões que faziam referência a "família ideal", a questão que defendia a função primordial do casamento associada à procriação passou a ser discordado no pós-teste, mediante a sensibilização estética. A princípio, as respondentes defenderam que o casamento tem como fator basilar a procriação. Talvez, esse aspecto esteja relacionado aos princípios religiosos, perceptíveis na defesa, tanto no pré- quanto no pós-teste, da afirmativa: "do ponto de vista religioso, a família constituída pelo homem e pela mulher é o modelo ideal de união" - o que vem complementar nossa suspeição.

Em seus estudos, Barcellos (2013, p. 17) aponta que essa prerrogativa, da família matrimonial decorre da intervenção da igreja nas relações afetivas, “[...] com o intuito de conservar a moralidade e os bons costumes, estabelecendo proibições de cunho cultural, ou seja, neste sistema, a família tem função reprodutiva somente, o único motivo do casamento é a procriação [...]". Após a intervenção, fundamentada na experiência estética, podemos constatar que esse conceito ruiu, ou seja, as educadoras passaram a discordar de que o casamento seja um instituto associado à perpetuação da espécie humana, mas uma organização que se “[...] constitui através da livre escolha dos cônjuges fundamentada no amor conjugal [...]" (HINTZ, 2001, p. 10). 
A produção desse novo sentido, após a intervenção com o cinema, foi propiciada pelo entrelaçamento das trajetórias de vida das participantes da pesquisa com as narrativas fílmicas, possibilitando que elas suspendessem seus preconceitos e estereótipos, acerca do ideário de família. Isto se deve ao fato de que a experiência as confronta com a evidência do limite de sua interpretação, levando-as a explorar distintas maneiras de compreender as famílias, o que permite uma abertura à diversidade de sentidos do mundo - isto é, de formas de sentir a realidade -, levando-as a compreender os reais fatores que permeiam essa instituição: o afeto e o respeito (HINTZ, 2001).

Em breves palavras, algumas das questões que versaram sobre o conceito de "família ideal" sofreram alterações nos momentos iniciais e finais da pesquisa. Se, a princípio, as participantes acreditavam que predominava a configuração familiar tradicional no cenário brasileiro, boa parte preferiu não opinar após a intervenção, talvez por dúvida quanto à informação. Ademais, enquanto preferiram manter a neutralidade na primeira aplicação do instrumento, boa parte passou a discordar que a família ideal é aquela regulada pelo Estado. Se antes, quase metade das respondentes discordou que as pessoas se casam com o intuito de procriar, após o Programa de Formação, um quarto das educadoras passou a discordar desse fato.

Baseado nessas premissas, os dados obtidos nesse aglomerado de questões reafirmam as discussões realizadas até o presente momento, de que a família ideal é aquela que consegue superar as adversidades e buscar soluções saudáveis para o desenvolvimento de seus membros e isso independe da sua configuração.

Nesse ponto de nossas discussões, devemos ressaltar dois pontos cruciais de nosso estudo, quanto à aplicação do instrumento baseado na Escala Likert. O primeiro se refere às questões que tratam da "família ideal", em que percebemos uma dubiedade nas assertivas: “a família ideal é aquela cujo núcleo é formado por pais e filhos unidos a partir do casamento regulado e regulamentado pelo Estado, considerada como família tradicional" e "o casamento é o único instituto formador e legitimador da família brasileira", pois ambas possuem basicamente o mesmo sentido conotativo e, logo, buscavam avaliar a mesma representação, sendo que a primeira sofreu variações estatísticas e a segunda não.

O segundo aspecto, detectado após a aplicação do teste baseado na Escala Likert, está amparado em Dalmoro e Vieira (2013), ao apontarem que o emprego de um questionário, nesse modelo, com três itens (concordo, não concordo e nem discordo e discordo), é indicado para pesquisas em que se busca diminuir o número total de opções 
a serem analisadas. Por exemplo, em nosso caso, um instrumento de 23 afirmativas, com escala de três pontos, englobará 69 opções a serem analisadas, em dois momentos, no pré- e pós-teste.

Porém, o número reduzido de opções de escolha encolhe o teste, ao mesmo tempo em que diminui sua eficiência para pequenas quantidades de respondentes, como é o nosso caso. Sendo assim, uma escala de três pontos não fornece uma boa discriminação das respostas, o que limita o método de análise dos dados.

Esse fator pode ter sido um interveniente no resultado de nossa pesquisa, já que pelo fato da amostra estudada ser reduzida não conseguimos aplicar a análise estatística do teste $t$-Student e tivemos poucas variações nas análises estatísticas empregando o teste de Wilcoxon. Portanto, indicamos para estudos futuros, que a escala de três pontos seja preterida em relação às escalas de cinco e sete pontos, caso o grupo amostral seja pequeno ou que se apliquem outros instrumentos na coleta de dados, que possibilitem a detecção de pequenas variâncias estatísticas.

\section{Considerações finais}

A experiência estética, por meio do cinema, permitiu as docentes romperem com o ideário de família tradicional, admitindo as diversas maneiras de ser família como verdadeiras. Consequentemente, cremos que as estratégias docentes adotadas por elas, daqui por diante, expandir-se-ão para o acolhimento de todas as famílias.

Esta afirmativa foi detectável, mediante a análise dos resultados do projeto de formação continuada, a re/des/construção dos conceitos docentes no que se refere às famílias organizadas em modelos não convencionais, aspecto este que confere força ao cinema enquanto ferramenta capaz de mobilizar sentidos e que, associada a outras estratégias, favorece a pedagogia do estético na mobilização de valores.

\section{REFERÊNCIAS}

ALVES, Leonardo Barreto Moreira. O reconhecimento legal do conceito moderno de família - o art. 5o, II e parágrafo único, da lei no 11.340/2006, Lei Maria da Penha. De Jure: revista jurídica do Ministério Público do Estado de Minas Gerais, Belo Horizonte, n. 8, p. 330-347, jan./jun. 2007. 
AMORIM, Verussi Melo de. Por uma educação estética: um enfoque na formação universitária de professores. 144 f. Dissertação (Mestrado em Educação) - Pontifícia Universidade Católica de Campinas, Campinas, 2007.

BANKS, Marcus. Dados visuais para pesquisa qualitativa. Tradução José Fonseca. Rev. Caleb Farias Alves. Porto Alegre: Artmed, 2009.

\section{BARCELLOS, Letícia Vasconcelos. A família homossexual vista pela}

jurisprudência constante. 50 f. Monografia (Graduação em Direito) - Universidade Regional do Noroeste do Estado do Rio Grande do Sul, Rio Grande do Sul, 2013.

BRONFENBRENNER, Urie. Ecological models of human development. In: International Encyclopedia of Education, 2. ed. Oxford: Elsevier, ano. v. 3. Reprinted In: GAUVANIAN, M. \& COLE, M. (Eds.), Readings on the development of children, 2. ed. NY: Frreman, 1994. p. 37-43.

DALMORO, Marlon.; VIEIRA, Kelmara Mendes. Dilemas na construção de escalas tipo Likert: o número de itens e a disposição influenciam nos resultados? Revista Gestão Organizacional, Chapecó, v. 6, p. 162-174, 2013.

HINTZ, Helena Centeno. Novos tempos, novas famílias? Da modernidade à pósmodernidade. Pensando famílias, Porto Alegre, n. 3, p. 8-19, 2001.

IBGE. Instituto Brasileiro de Geografia e Estatística. Censo 2010. [S.1.], 2010. Disponível em: <http://censo2010.ibge.gov.br/>. Acesso em: 19 jan. 2016.

KEHL, Maria Rita. Em defesa da família tentacular. Artigos e Ensaios. [S.1.], 2003. Disponível em:

<http://www.mariaritakehl.psc.br/PDF/emdefesadafamiliatentacular.pdf >. Acesso em: 17 jul. 2014.

OLIVEIRA JÚNIOR, Isaias Batista de.; MORAES, Dirce Aparecida Foletto de.; COIMBRA, Renata Maria. Família "margarina": as estereotipias de famílias na indústria cultural e a des/re/construção de conceitos docentes. HISTEDBR On-line, Campinas, n. 64, p. 266-279, set. 2015.

PEREIRA, Rodrigo da Cunha. Princípios fundamentais e norteadores para a organização jurídica da família. 2004. 157 f. Tese (Doutorado em Direito) Universidade Federal do Paraná, Curitiba, 2004.

ROUDINESCO, Elisabeth. A família em desordem. Tradução André Telles. Rio de Janeiro: Jorge Zahar, 2003.

SIEGEL, S. Nonparametric Statistics for the behavioral sciences. New York: McGraw-Hill Book Company, 1956.

WAGNER, Adriana. Os desafios da família contemporânea: revisitando conceitos. In: WAGNER, Adriana et al. Desafios psicossociais da família contemporânea: pesquisas e reflexões. 1. ed. Porto Alegre: Artmed. 2011. p. 19-35. 
WALSH, Froma. Fortalecendo a resiliência familiar. Tradução Magda França Flores. Revisão Científica Cláudia Bruscagin. São Paulo: Roca, 2005.

\section{Como citar este artigo:}

OLIVEIRA JÚNIOR, Isaias Batista de. Em cartaz: a formação docente e as representações de famílias organizadas em modelos não convencionais. Revista on line de Política e Gestão Educacional, Araraquara, v.21, n.2, p. 542-562, maio-ago. 2017. Disponível em: 〈http://dx.doi.org/10.22633/rpge.v21.n.2.2017.9955>. ISSN: 15199029.

Submetido em: 05/06/2017

Aprovado em: 20/07/2017 